\title{
A Proposed Prototype Evaluation Instrument in Filipino 1 in State Universities in Tacloban City
}

\author{
Dr. Alvin Rom De Mesa \\ Leyte Normal University Tacloban City, Philippines \\ Email Address: ar demesa@ymail.com
}

\begin{abstract}
:
This study focused on the development of a proposed prototype evaluation instrument in Filipino 1. Specifically, the study sought to answer the following questions: What proposed prototype evaluation instrument should be developed in Filipino 1? What intervention scheme may be proposed to improve the academic performance of education students of the Leyte Normal University and Eastern Visa as State University? The study used the descriptive developmental research with fifty (50) First Year Education students for the first dry run at Leyte Normal University, and another set of fifty (50) First Year Education students for the final dry run was conducted at Eastern Visayas State University; and Fifty (50) First Year Education students for establishing reliability of the final form of the evaluation instrument in Filipino 1, conducted at Leyte Normal University with a combined coefficients of 0.72 which was interpreted as having a "high reliability."To determine whether the Proposed Prototype Evaluation Instrument in Filipino 1 is valid and reliable, the following were considered: Validation of the evaluative instrument as determined by the panel of evaluators; administering the evaluation instrument at Leyte Normal University for the first dry run and Eastern Visayas State University for the final dry run; item analysis, after the dry runs; and lastly, analyzing the distracters where the conditional and not effective distracters were removed or changed.
\end{abstract}

\section{Introduction:}

The Commission on Higher Education (CHED) Memorandum Order No. 30, series of 2004, providing for the revised policies and standards for undergraduate teacher education curriculum was implemented effective school year 2005-2006.

The memorandum emphasized the new subjects to be offered in the Bachelor of Secondary Education, Bachelor of Elementary Education, and any Professional course offered in the Philippines. One of the basic subjects in all teacher education courses is Filipino 1 with the descriptive title, "Kontekstwalisadong Komunikasyonsa Filipino." All private higher education institutions (PHEIs), and state universities and colleges (SUCs) are strongly encouraged to implement the memorandum in their respective schools not only for global competitiveness but also for the preparation of their graduates in taking the Licensure Examination for Teachers (LET) (CHED Memorandum Order No. 30, s. 2004).

Every university needs a way of sorting out how well its products, services, practices, projects, systems, policies, and programs is gaining value. This calls for an evaluation instrument which is used across disciplines. An evaluation instrument is done for improving the system, helping make decisions about the best course of action, and learning about the reasons for successes and failures (Stacy\& Whittaker, 2005).

Educational planners routinely evaluate organizations, institutions, policies, strategies, programs, projects, products, services, systems, processes, performance, job candidates, jobs, and proposals. Evaluation is done to arrive at valid conclusive decisions (Rivkin, Bruce, \& Blake, 2005).

Tests of all kinds have proliferated in the last fifty years. The use of tests as diagnostic and predictive devices in the elementary, secondary, and tertiary schools has markedly increased. Procedures for selecting government employees ordinarily include tests, and the armed services tailor-make hundreds of different tests to ensure the most appropriate placement of individuals (Bennett, Wesley,\& Dana-Wesley, 1999). The 
Department of Education, too, in its selection and placement of teachers has come to rely heavily upon various measuring devices, one of which is the Licensure Examination for Teachers. That is why; this Office has a policy of no-license-no item to an applicant who would like to teach in the public schools.

Many, if not most, Filipino subject teachers prefer to wait until they avail themselves of a prototype evaluation instrument (usually a workbook) before they attempt to come up with their own testing instrument. The question becomes: "Is a high-fidelity prototype evaluation instrument necessary to have a meaningful usability test?" A high-fidelity prototype is CHED Memo-based, and usually has processes to be followed in order to make it valid and reliable. A low-fidelity prototype is usually made in an easy way, in which they may not follow the cognitive domain processes of Bloom's Taxonomy of Objectives that make the prototype valid, and reliable (Walker, Takayama, \& Landay, 2002).

The purpose of this study was to develop a Proposed Prototype Evaluation Instrument in Filipino 1.This study sought to identify the following: 1 . what proposed prototype evaluation instrument could be developed in Filipino 1? and, 2. What intervention scheme may be proposed to improve the academic performance of education students of the Leyte Normal University and Eastern Visayas State University?

It is in this context that the researcher has thought to conduct a research which is a prototype evaluation instrument in Filipino 1 which will be helpful for those in Higher Education who wish to take advantage of this evaluative material into their teaching (Stoner, 2000).

\section{Methodology:}

This section presents the research design, research locale, respondents of the study, research instrument, data gathering procedure, method of data analysis and statistical treatment.

\section{Research Design}

This study used the descriptive developmental research design for the evaluation instrument. The syllabus, Table of Specifications, 3-point rating scale and proposed prototype evaluation instrument in Filipino 1 were used. The study sought to develop a prototype evaluation instrument in Filipino 1 and the intervention scheme that may be evolved to improve the academic performance of education students of Leyte Normal University (LNU) and Eastern Visayas State University (EVSU) in Tacloban City.

\section{Research Locale}

This study was conducted in a Teacher Training Institution and a State Technological University in Tacloban City namely, Leyte Normal University (LNU) and Eastern Visayas State University (EVSU). These universities are offering education courses on which the main concern of this study is focused. The map below shows the location of LNU and EVSU in Tacloban City.

\section{Respondents of the Study}

The respondents of the study were selected First Year Education students during the Second Semester of School Year 2008-2009. They are identified using a random sampling technique. Leyte Normal University had 806 First Year Education Students while Eastern Visayas State University had only 297 education students. The researcher opted for the same number of respondents in the two state universities; fifty (50) randomly selected education students from Leyte Normal University were considered for the first dry run; fifty (50) randomly selected education students from Eastern Visayas State University were considered for the second dry run; and from the master lists given from the two universities, the systematic random sampling technique was used; the said instrument was evaluated, particularly its content and face validity by a panel of three experts in Filipino. These universities are the only SUCs in Leyte which fully implemented the new curriculum in their education courses.

\section{Research Instruments}

Four instruments were used in this study: First is the Syllabus in Filipino 1. This was suggested by CHED for implementing its new curriculum and this is appended as Appendix B. This instrument contained the topics for the entire semester; the Table of Specifications was the guide of the researcher in making the Proposed Evaluation Instrument in Filipino 1. This instrument was composed of topics, cognitive processes, total, and percentage; then an Evaluative Instrument in Filipino 1 was devised by the researcher. This is the main objective why this study conducted. This instrument is similar to the other instructional materials in the workbook; and, fourth, a Rating Scale composed of two parts, Part I for Content Validity and Part II 
for Face Validity, appended as Appendix D, an instrument where the panel of Filipino experts gave their judgment whether the proposed prototype evaluation instrument in Filipino 1 was good in terms of the following criteria: For Content validity - The stem is based on the Syllabi and Table of Specifications; the stem present a clear problem; the correct response is adequate and better than the other; the distracters are likely to attract mainly the students of low achievement; For Face validity - Format; page lay-out; language; the items are clearly stated; the words are clearly printed and legible; and the directions are concise and clear (Bennett, Clinton, Huge, \& Parker, 1996).

\section{Data-Gathering Procedure}

Before the conduct of the study, a permit to conduct the study was sought from the Presidents, Deans, and Department Heads of the identified Universities.

In the development of the evaluative instrument in Filipino 1, the following were considered: Instructional specifications, Determining the content of the test, Preparing the Table of Specifications, Selecting appropriate format, Constructing the Test Items, constructing the Proposed Prototype Evaluation Instrument in Filipino 1 and the achievement test Item Validation, First and Second dry runs, item analysis, content and face validity, reliability and final revision of the Proposed Prototype Evaluation Instrument in Filipino 1(Biggs, 1987).

Instructional specifications. This was the first step in the development of the Proposed Prototype Evaluation Instrument in Filipino 1 (Calderon \& Gonzales, 1998).

Determining the content of the test. The intention of the Proposed Prototype Evaluation instrument was to make a workbook which evaluates the acquired knowledge, concepts and skills of the students who are taking Filipino 1. This material contains the subject matter and the kind of behavior expected of the First Year Education students of Leyte Normal University and Eastern Visayas State University. Based on the syllabus, as suggested by CHED, the contents of the evaluation instrument were determined (Kim, Dame wood,\& Hodge, 2000).

Preparing the Table of Specifications. In order to have a balanced distribution of the items in different competencies in the syllabus, a two grid Table of Specification was constructed. The Table consists of the scope of the subject matter, the cognitive processes, the total number of items in every subject matter and the percentage based on the syllabus of Filipino 1, the total number of items in every topic, and the percentage (Mohanty, Gretes, Flowers, Algozzine, \& Spooner, 2005).

Selecting appropriate format. A multiple-choice type of questions was used in the instrument. The test constructor of the test provided several possible answers (in this study four were used) from which the examinees must choose. There is one right answer, usually represented by one answer option, though sometimes divided into two or more, all of which subjects must identify correctly (Monahan, 1998). Test authors generally create incorrect response options, often referred to as distracters, which correspond with likely errors. For example, distracters may represent common misconceptions that occur during the developmental process. According to Padua (1997), the formula of difficulty index is most appropriate in identifying the best distracters. If the result is negative, it means effective distracters, if it is positive, it is ineffective distracters, and if it is zero, this means that the distracter needs for improvement.

Constructing the Test Items. There were two parallel items constructed. Each competency includes the preliminary version of the test to give allowance for discarding the undesirable items. Each item was constructed in such a way that it would measure directly one of the specific objectives of the subject (De Mesa, 2002).

Proposed Prototype Evaluation Instrument and Achievement Test Item Validation. The constructed Evaluation Instrument and Achievement Test with the copy of a syllabus, the 3-point rating scale and the Table of Specifications were submitted to the validity panel for content and face validation and for suggestions on the improvement of the proposed prototype evaluation instrument in Filipino 1.

First and Second Dry Runs. The first dry run was conducted at Leyte Normal University, then, the second dry run was conducted at Eastern Visayas State University. 
Item Analysis. This was done every after each dry run in order to identify which items are discarded and to improve the proposed prototype evaluation instrument in Filipino 1. After administering the first dry run to the LNU students, item analysis was conducted. The U-L method was used to identify the effective items and distracters.

Content and Face Validity. This is the validation of the Evaluative Instrument in the development of the proposed prototype evaluation instrument in Filipino 1. There were three panel of evaluators who evaluated the said instrument.

Final Revision. The evaluation instrument in this step was good in terms of difficulty and discrimination indices, as well as the distracters in the development of the proposed prototype evaluation instrument in Filipino 1 where a workbook or exercises were developed (Padit, 2006).

Reliability. To identify the reliability of evaluative instrument in Filipino 1, fifty selected education students of Leyte Normal University were considered in this step. According to Oriondo and Antonio (2002), the reliability of evaluation instrument in Filipino 1 refers to the consistency of scores obtained by the same person when retested by the same test or by an equivalent form of the test. This means that the same 50 students took the test.After the permit was granted, the researcher went to the universities involved in the study. Prior to answering the evaluative instrument in Filipino 1, respondents were briefed by the researcher on the purpose of the research work and the manner of using the answer sheet (Bernales, 2006). Retrieval of the evaluative instruments was done right after the respondents answered all the items of the test.After the instruments were retrieved, the answers of the respondents were sorted out, tabulated, and statistically analyzed.

\section{Method of Data Analysis}

The data gathered in this study were processed, with the researcher adopting the scoring and statistical tools for purposes of classifying the numerical values with their corresponding descriptions and interpretations (Hidalgo, 2005).

Content and Face Validity. To interpret the results on content and face validity, the following categories were used:

\begin{tabular}{|c|c|}
\hline Range for Content and Face Validity & Interpretation \\
\hline 3 & Very Satisfactory \\
\hline 2 & Satisfactory \\
\hline 1 & Below Satisfactory \\
\hline
\end{tabular}

Difficulty Index. To get the exact description of the difficulty index, the following results are interpreted:

\begin{tabular}{|c|c|}
\hline Difficulty Index & Interpretation \\
\hline $0.81-$ above & Very Easy Item \\
\hline $0.61-0.80$ & Easy Item \\
\hline $0.41-0.60$ & Moderately Difficult Item \\
\hline $0.21-0.40$ & Difficult Item \\
\hline $0.00-0.20$ & Very Difficult Item \\
\hline
\end{tabular}

Discrimination Index. To get the exact description of the discrimination index, the following results are interpreted:

\begin{tabular}{|c|c|}
\hline Index of Discrimination & Interpretation \\
\hline+0.61 to +1.00 & Very Discriminating Item \\
\hline+0.21 to +0.60 & Discriminating Item \\
\hline-0.21 to +0.20 & Moderately Discriminating Item \\
\hline-0.59 to -0.20 & Not Discriminating Item \\
\hline
\end{tabular}


Dr. Alvin Rom De Mesa /A proposed Prototype Evaluation Instrument in Filipino 1 in State Universities in Tacloban City

\begin{tabular}{|l|c|}
\hline-1.00 to -0.60 & Questionable Item \\
\hline
\end{tabular}

Combined Judgment of Discrimination Indices. The following are considered on its interpretation.

\begin{tabular}{|c|c|c|}
\hline Difficulty Level & Discriminating Level & Action/Judgment \\
\hline \multirow{4}{*}{ Very Difficult } & Not Discriminating & Improbable; discard \\
\cline { 2 - 3 } & Moderately Discriminating & May Need Revision \\
\cline { 2 - 3 } & Discriminating & Accept \\
\hline \multirow{3}{*}{$\begin{array}{c}\text { Difficult - Moderately } \\
\text { Difficult }\end{array}$} & Not Discriminating & Needs Revision \\
\cline { 2 - 3 } & Moderately Discriminating & May Need Revision \\
\cline { 2 - 3 } & Discriminating & Accept \\
\hline \multirow{3}{*}{ Easy } & Not Discriminating & Discard \\
\cline { 2 - 3 } & Moderately Discriminating & Needs Revision \\
\cline { 2 - 3 } & Discriminating & Needs Revision \\
\hline \multirow{3}{*}{ Very Easy } & Not Discriminating & Discard \\
\cline { 2 - 3 } & Moderately Discriminating & Needs Revision \\
\cline { 2 - 3 } & Discriminating & Needs Revision \\
\hline
\end{tabular}

Distracters. Action for Distracters of each item were:

\begin{tabular}{|c|c|}
\hline Result & Interpretation/Action \\
\hline If there is Negative sign (-) & Effective Distracters \\
\hline If there is Positive sign (+) & Not Effective Distracters \\
\hline If it is Zero & Conditional Distracters \\
\hline
\end{tabular}

Index of Reliability. The reliability of the Evaluation Instrument in Filipino 1 was categorized and interpreted as follows:

\begin{tabular}{|c|c|}
\hline Correlation Coefficient & Interpretation \\
\hline $0.91-0.99$ & Very High Reliability \\
\hline $0.71-0.90$ & High Reliability \\
\hline $0.41-0.70$ & Marked or Moderately Reliable \\
\hline $0.21-0.40$ & Slightly Reliable \\
\hline $0.00-0.20$ & Negligibly Reliable \\
\hline
\end{tabular}

\section{Statistical Treatment}

For the analysis and interpretation of data, the following treatment was employed. The formula for Difficulty Index of each Item was:

$$
\mathrm{D}=\frac{\mathrm{U}+\mathrm{L}}{\mathrm{N}}
$$

Where:

D - Level of difficulty index of the item.

U - Total number of the students who got the correct answer Above 27\%.

L - Total number of students who got the correct answer below $27 \%$.

The formulas for Discrimination index of Each Item were:

$$
\mathrm{U}-\mathrm{L}
$$




$$
\text { Di }=
$$

\section{Where:}

$$
1 / 2 \mathrm{~N}
$$

Di - Discrimination Index of the item.

$\mathrm{Nu}$ - Total number of students in the upper group who answered the item correctly.

$\mathrm{Nr}$ - Total number of students in the lower group who answered the item correctly.

$1 / 2 N$ - One half of the total number of respondents in the item analysis.

\section{Determining the Reliability}

Mean (X)

$$
(X)=\frac{\sum N}{N}
$$

Where:

$\Sigma \mathrm{N}=$ Sum or summation of all scores

$\mathrm{N}=$ Total number of test takers

$$
\underset{\partial^{2}}{\operatorname{Variance}\left(\partial^{2}\right)}=\frac{\mathrm{n} \Sigma \mathrm{x}-\left(\sum \mathrm{x}\right)^{2}}{\mathrm{n}(\mathrm{n}-1)}
$$

Where:

$\mathrm{n} \Sigma \mathrm{x} \quad=\quad$ The sum products

$(\Sigma \mathrm{x})^{2} \quad=\quad$ The sum of squared products

Reliability $\left[\begin{array}{l}\mathrm{r} \\ \mathrm{KR} 21]\end{array}\right]$

The Kuder Richardson Formula 21 will be used in this study were the formula is (Oriondo and Antonio:2002):

$\mathrm{r} R 21=\frac{\mathrm{K}}{\mathrm{K}-1}\left[1-\frac{\mathrm{M}\left[\begin{array}{cl}1- & \mathrm{M} \\ \mathrm{K}\end{array}\right]}{\partial^{2}}\right)$

Where:

$\mathrm{r}$

KR21 - The Reliability index of the Test

$\mathrm{K} \quad$ - The Total Number of Items of the Test

$(\bar{X}) \quad-\quad$ The Mean Score of all examinees who took the test

$\partial^{2} \quad-\quad$ The Variance

\section{Results And Discussion:}

This section illustrates the combined judgment of content and face validity, the results of item analysis of the final dry run, the effectiveness of the distracters, the reliability of the Proposed Prototype Evaluation Instrument in Filipino 1 and its final form, and the discussion on the intervention scheme that may be proposed in improving the academic performance of education students of Leyte Normal University and Eastern Visayas State University. 


\section{On the Content Validity}

Table I presents the mean indicators of the content validity of the Proposed Prototype Evaluation Instrument in Filipino 1. The criteria are shown with their computed means and their corresponding interpretations. The combined mean of the Content Validity of the Proposed Prototype Evaluation Instrument in Filipino 1 is "very satisfactory" with 2.84. This means that the panel of evaluators agreed on the following criteria of the content validity of the said instrument: That the items are based on the Filipino 1 syllabus, the Items present clear problems, the correct responses are better than the other responses, and the distracters are likely to attract mainly students of low achievement (Petilos, 2002).

Table 1. The Content Validity of the Proposed Prototype Evaluation Instrument in Filipino 1

\begin{tabular}{|c|l|c|c|}
\hline \multicolumn{2}{|l|}{ Criteria } & Mean & Interpretation \\
\hline 1 & The items are based on the Filipino 1 Syllabus. & 2.67 & Very Satisfactory \\
\hline 2 & The Items present clear problems. & 3.00 & Very Satisfactory \\
\hline 3 & The correct responses are better than the other responses. & 2.67 & Very Satisfactory \\
\hline 4 & Combined Mean & & \\
& The distracters are likely to attract mainly students of low achievement. & 3.00 & Very Satisfactory \\
\hline \multicolumn{2}{|c|}{ Com } & Very Satisfactory \\
\hline
\end{tabular}

This implies that the panel of evaluators agreed that the Content Validity of the Proposed Prototype Evaluation Instrument in Filipino 1 was very satisfactory.

\section{Face Validity}

Table 2 shows the mean indicators of the Face Validity of the Proposed Prototype Evaluation Instrument in Filipino 1. The criteria are shown with their computed means and their corresponding interpretations. Table illustrates the mean indicators of the face validity of the proposed prototype evaluation instrument in Filipino 1. As illustrated in the Table, the panelof evaluators believed that the said instrument is very satisfactory, with a combined mean of 2.89, with the following criteria: The Table presents that the Proposed Prototype Evaluation Instrument in Filipino 1 is appropriate in terms of format, page lay-out, and language, the items are clearly stated, the words are clearly printed and legible, and the directions are concise and clear (Hilario, 1999).

\section{Table 2. The Face Validity of the Proposed Prototype Evaluation Instrument in Filipino 1}

\begin{tabular}{|c|l|c|c|}
\hline No. & \multicolumn{1}{|c|}{ Criteria } & Mean & Interpretation \\
\hline \multirow{4}{*}{1} & $\begin{array}{l}\text { The Proposed Prototype Evaluation Instrument in Filipino 1 is } \\
\text { appropriate in terms of: }\end{array}$ & $\mathbf{2 . 8 9}$ & Very Satisfactory \\
\cline { 2 - 4 } & a. Format & 3.00 & Very Satisfactory \\
\cline { 2 - 5 } & b. Page Lay-out & 3.00 & Very Satisfactory \\
\cline { 2 - 5 } & c. Language & 2.67 & Very Satisfactory \\
\hline 2 & The Items are Clearly Stated & 3.00 & Very Satisfactory \\
\hline 3 & The words are clearly printed and legible. & 3.00 & Very Satisfactory \\
\hline 4 & The directions are concise and clear. & 2.67 & Very Satisfactory \\
\hline \multicolumn{2}{r}{ Combined Mean } & $\mathbf{2 . 8 9}$ & Very Satisfactory \\
\hline
\end{tabular}

This implies that the panel of evaluators showed that the Face Validity of the Proposed Prototype Evaluation Instrument in Filipino 1 was also very satisfactory. They appreciated that the evaluation instrument is very appropriate in those criteria.The proposed Prototype Evaluation Instrument in Filipino 1 constructed in this study consisted of three parts, namely: Chapter 1 is on Metalinggwistikna Pagtalakaysa Wikang Filipino, Chapter 2 is Diskurso at Komunikasyon and Chapter 3 is on Apatna Makrong Kasanayan. 
Total number of items in every set of exercises

Table 3 shows the three chapters of the evaluation instrument with their corresponding total number of items.

Table 3. Number of items of the Proposed Prototype Evaluation Instrument in Filipino 1

\begin{tabular}{|c|c|c|c|c|c|}
\hline $\begin{array}{c}\text { Exercises } \\
\text { Chapter 1 }\end{array}$ & $\begin{array}{c}\text { Total No. } \\
\text { of Items }\end{array}$ & $\begin{array}{c}\text { Exercises } \\
\text { Chapter 2 }\end{array}$ & $\begin{array}{c}\text { Total No. of } \\
\text { Items }\end{array}$ & $\begin{array}{c}\text { Exercises } \\
\text { Chapter 3 }\end{array}$ & $\begin{array}{c}\text { Total No. of } \\
\text { Items }\end{array}$ \\
\hline 1 & 40 & 1 & 50 & 1 & 60 \\
\hline 2 & 30 & 2 & 55 & 2 & 60 \\
\hline 3 & 55 & & & 3 & 40 \\
\hline 4 & 40 & & & 4 & 40 \\
\hline 5 & 20 & & & & \\
\hline 6 & 50 & & & & \\
\hline
\end{tabular}

As illustrated in Table 3, there were corresponding total number of items of each exercise as based on the computed results in distributing the expected items in every chapter. The computed results were based on the number of hours to be conducted of each topic of the entire semester where Filipino 1 is offered.It implies the exact number of every exercise from Chapter 1 to 3. The six (6) exercises in Chapter 1 represent the six sub-topics, two exercises in Chapter 2 represent two sub-topics, and in Chapter 3, there were four exercises made as represented by four sub-topics.

\section{Conclusions:}

The following conclusions were drawn based on the findings: First, the constructed proposed prototype evaluation instrument in Filipino 1 has a balanced distribution as shown in the Table of Specifications which are valid and reliable. And, second, the intervention scheme to improve the academic performance of the First Year Education students in State Universities in Tacloban City must focus on the capability of the teachers who are handling the subject by mentoring, making syllabus, constructing, and using evaluation instrument that is valid and reliable. Based on the findings and conclusions, the following recommendations are advanced with the hope that these will be considered for implementation: First, the Filipino Unit or Department of the two state universities in Tacloban City should use the proposed prototype evaluation instrument in Filipino 1 in order to evaluate their students' performance. Second, any evaluation instrument must be relevant to the present curriculum especially in education courses for them to be prepared in taking the Licensure Examination for Teachers (LET). Third, the proposed Intervention Scheme contained in this study be given due consideration by the administrations of the two state universities covered in this research. Fourth, CHED Memo No. 30. s. 2004 should be implemented in all state colleges and universities in Region VIII. Fifth, Similar studies should be conducted in other Filipino and non-Filipino subjects to be used in evaluating the performance of the students taking the subjects. Ang lastly, sixth, the future researchers may use this study for guidance in making a research similar to this.

\section{References:}

[1] Bernales, R. A. (2006).Locally-funded higher education institutions' research culture: A proposed model. Dissertation. University of Makati, Philippines. 2006.

[2] Bennett, Clinton, Huge. L. S., \& Parker, T. (1996). Researching into teaching methods in colleges and universities, Kogan Page, London.

[3] Bennett, D. T., Wesley, H., \& Dana-Wesley, M. (1999). Planning for imminent change in college admissions: Research on alternative admissions criteria. Journal of College Student Retention.

[4] Biggs, J.B. (1987). Student approaches to learning and studying. Melbourne: Australian Council for Educational Research.

[5] Calderon, J. F. and Gonzales, E. C. (1998).Measurement and evaluation. Mandaluyong City: National Book Store Inc. 
[6] De Mesa, A. R. (2002).Prototype qualifying examination for Filipino majors. Master's Thesis, Leyte Normal University, Tcaloban City, Philippines.

[7] Hidalgo, M. O. (2005).Isang prototype na kagamitang pagsusulit sa filipino para saikatlongtaonbataysabinagong kurikulum. Master's Thesis, Leyte Normal University, Tacloban City, Philippines.

[8] Hilario, R. B. (1999).A Proposed Alternative training Program Model for schools superintendents in region VIII. Master's Thesis, Leyte Normal University, Tacloban City, Philippines.

[9] Kim, C., Dame wood, E., \& Hodge, N. (2000).Professor attitude: Its effect on teaching evaluations. Journal of Management Education,24 (4).

[10] Mohanty, G., Gretes, J., Flowers, C., Algozzine, B., \& Spooner, F. (2005). Multi-method evaluation of instruction in engineering classes. Journalof Personnel Evaluation in Education, 18 (2), 139-151. 2005.

[11] Monahan, T. (1998).The rise of standardized educational testing in the USA Bibliographic Overview.

[12] Padua, R. N. and Santos. (1997). Educational evaluation and measurement: Theory, practice and application. Quezon City, Philippines: Katha Publishing Co.

[13] Padit, F. C. (2006). Selected factors and academic performance of the third-year bachelor of science in education students in eastern samarstate university. Master's Thesis, Leyte Normal University, Tacloban City, Philippines.

[14] Petilos, G. P. (2002).Constructivist model for teaching problem solving:Effects on students' problem-solving and critical thinking skills. Doctoral Dissertation, University of the Philippines, Open University.

[15] Rivkin, S. G. Bruce, W., \& Blake J. M. (2005).Teachers, schools, and academic achievement. Econometrica, Econometric Society, vol. 73 (2), pp. 417- 458.

[16] Stacy, G. D. and Whittaker, J. M. (2005).Predicting academic performance and clinical competency for international dental students: Seeking the most efficient and effective measures. American Dental Association.

[17] Stoner, G. (2021) Implementing Learning Technology. Retrieved on October 5, 2021, from http://www.icbl.hw.ac.uk/ltdi/ltdi-pub.htm.

[18] Walker, M., Takayama, L. and Landay, J.A. (2002).High-fidelity or low- fidelity, paper or computer? Choosing attributes when testing web prototypes, Proceedings of the Human Factors and Ergonomics Society 46th Annual Meeting. 